\title{
PELATIHAN STRUKTUR KOMUNIKASI SBAR BAGI TENAGA KESEHATAN DI RUMAH SAKIT UNIVERSITAS MATARAM
}

\author{
Dian Puspita Sari ${ }^{*}$ ), Yoga Pamungkas Susani, Mohammad Rizki, Titi Pambudi \\ Karuniawaty \\ Program Studi Pendidikan Dokter Universitas Mataram \\ Jalan Pendidikan No 37 Mataram \\ *alamat korespondensi: dianps@unram.ac.id
}

\begin{abstract}
ABSTRAK
Komunikasi antar tenaga kesehatan terkait informasi perawatan pasien menjadi sangat penting untuk menjamin keberlanjutan perawatan dan keselamatan pasien. Masalah komunikasi yang berujung pada tuntutan malpraktik sering ditemukan pada proses handoff, yaitu ketika tanggung jawab perawatan pasien dialihkan ke tenaga kesehatan lain. SBAR (Situation, Background, Assessment, dan Recommendations) merupakan suatu pendekatan komunikasi kolaboratif yang direkomendasikan oleh WHO untuk membantu para klinisi agar memiliki pemahaman yang sama mengenai kondisi klinis pasiennya sehingga dapat mengatasi berbagai hambatan dalam berkomunikasi. Tujuan dari pelatihan ini adalah untuk meningkatkan pengetahuan dan kemampuan dokter dan tenaga kesehatan yang bertugas di Rumah Sakit Universitas Mataram mengenai penerapan metode komunikasi SBAR dalam proses handoff pasien. Pelatihan ini diikuti oleh 46 orang perawat, bidan, dokter dan tenaga kesehatan lain yang bertugas di RS Universitas Mataram. Kegiatan Pengabdian Kepada Masyarakat ini dilakukan dengan metode ceramah, dibantu dengan media video sebagai pemicu diskusi dan tanya jawab mengenai proses handoff serta simulasi penerapan SBAR dalam bentuk role-play menggunakan kasus-kasus yang disiapkan. Peserta melakukan evaluasi diri setelah mengikuti role-play dan mendiskusikan umpan balik dari fasilitator dan peserta lainnya. Berdasarkan hasil pre dan postes, didapatkan peningkatan pengetahuan yang signifikan mengenai proses handoff dan struktur SBAR dari 4.69 menjadi 7.27. Berdasarkan hasil evaluasi diri sebelum dan sesudah pelatihan didapatkan peningkatan pemahaman mengenai situasi yang membutuhkan komunikasi handoff, struktur SBAR, cara melakukan handoff dan kemampuan menerapkan SBAR. Peserta menilai pelatihan SBAR relevan dan bermanfaat bagi tugas pekerjaan mereka dan sesi role-play sangat bermanfaat untuk melatih keterampilan mereka menggunakan struktur SBAR.
\end{abstract}

Kata kunci: SBAR, komunikasi, handoff, role-play 


\section{PENDAHULUAN}

Pasien yang menjalani perawatan di Rumah Sakit dilayani oleh banyak tenaga kesehatan dengan tugas dan fungsi yang berbeda-beda. Selama proses perawatan, tanggung jawab perawatan pasien dapat dialihkan dari satu tenaga kesehatan ke tenaga kesehatan lainnya di antara sesi jaga, ataupun dari satu bagian ke bagian lainnya. Selain itu, pada saat yang sama tanggung jawab terhadap perawatan pasien juga tersebar di antara penyedia layanan yang berbeda. Oleh karena itu, komunikasi antar tenaga kesehatan terkait informasi perawatan pasien menjadi sangat penting untuk menjamin keberlanjutan perawatan. Pengalihan tanggung jawab perawatan pasien dari satu pihak ke pihak lain dikenal sebagai proses handof" atau serah terima pasien. Handoff merupakan kegiatan tukar menukar informasi yang terjadi pada saat tenaga kesehatan (dokter, perawat atau lainnya) mengambil alih tanggung jawab terhadap pasien. Fokus utama kegiatan ini adalah untuk menyediakan informasi mengenai pasien kepada pihak penerima yang akan meningkatkan efektivitas dan aspek keselamatan (safety) tindakan yang akan dilakukan pihak penerima informasi (Cohen \& Hilligos, 2010).

$$
\text { Terlepas dari pentingnya }
$$

komunikasi pada saat melakukan handoff, komunikasi yang buruk antar anggota tim perawatan tidak jarang dijumpai dan seringkali berhubungan dengan kejadian yang tidak diharapkan. Hasil review oleh The Joint Comission on the Accreditation of Healthcare Organizationsterhadap hampir 2,500 sentinel events atau kejadian tidak diharapkan di berbagai Rumah Sakit di Amerika menunjukkan bahwa komunikasi merupakan akar masalah primer yang berkontribusi terhadap 70\% kejadian; hal ini menjadi sangat serius karena hampir 75\% pasien dalam kejadian tersebut kehilangan nyawanya (JCHAO, 2004 dalam Leonard et al., 2004).

Berbagai penelitian menunjukkan bahwa masalah dalam komunikasi sering ditemukan pada proses handoff, yaitu ketika tanggung jawab perawatan pasien dialihkan ke tenaga kesehatan lain. Petersen et al. (1994 in Cohen et al., 2012) juga menemukan adanya peningkatan kejadian tidak diharapkan yang seharusnya dapat dicegah sebanyak dua kali lipat pada pasien-pasien yang ditangani oleh dokter jaga on-call dari tim yang berbeda dengan tim yang menangani pada jam kerja reguler. Selain itu, proses handoff juga terlibat dalam 28\% kesalahan bedah (Gawande et al., 2003 dalam Cohen et al., 2012) dan 20-24\% klaim malpraktek pada berbagai situasi pelayanan kesehatan seperti rawat jalan (Gandhi et al., 2006 dalam Cohen et al., 2012) dan 
pelayanan gawat darurat (Kachalia et al., 2007 dalam Cohen et al., 2012). Karena proses handoff tidak dapat dihindari dalam proses perawatan pasien di RS, maka seluruh pihak yang terlibat dalam proses perawatan harus memiliki shared mental model,yaitu persepsi, pemahaman atau pengetahuan yang sama di antara anggota suatu tim, mengenai situasi atau proses tertentu yang dicapai melalui komunikasi (AHRQ, 2012). Secara spesifik, Joint Commission on National Patient Safety Goal pada tahun 2006 merekomendasikan pendekatan standar untuk berkomunikasi dalam proses handoff, termasuk kesempatan untuk bertanya dan menjawab pertanyaan. Rekomendasi yang sama juga diberikan oleh WHO Collaborating Centre for Patient Safety Solutions (2007).

SBAR (Situation, Background, Assessment, dan Recommendations) merupakan suatu pendekatan komunikasi kolaboratif yang berasal dari Angkatan Laut Amerika Serikat. Metode ini diperkenalkan ke dalam dunia kesehatan oleh Michael Leonard dari Kaiser Permanente - Denver, untuk membantu klinisi memiliki pemahaman yang sama mengenai kondisi klinis pasiennya (Haig et al., 2006; Beckett \& Kipnis, 2009). Penggunaan teknik SBAR merupakan bagian dari rekomendasi WHO Collaborating Centre for Patient Safety
Solutions (2007) disamping alokasi waktu khusus untuk berdialog dan penyediaan informasi klinis yang penting mengenai pasien.

Penggunaan SBAR sebagai teknik komunikasi bermanfaat untuk mengatasi berbagai hambatan dalam berkomunikasi. Hambatan - hambatan ini antara lain adalah absennya pihak yang bertanggung jawab terhadap perawatan pasien, hierarki, jenis kelamin dan latar belakang etnis. Selain itu, perbedaan gaya komunikasi antara perawat dan dokter juga merupakan faktor penting yang berkontribusi. Karena pendekatan yang digunakan dalam proses pendidikannya, perawat cenderung sangat deskriptif dan detil dalam berkomunikasi sementara dokter cenderung merangkum informasi dalam pernyataan-pernyataan singkat. Perbedaan gaya komunikasi ini sering menjadi penghambat dalam komunikasi dokter dengan perawat (Leonard et al. 2004; Haig et al., 2006). Dalam mengatasi hambatan-hambatan ini, teknik SBAR (tabel 1) mengkondisikan pihak-pihak yang berkomunikasi menggunakan cara berpikir yang sama (shared mental model) dengan memberikan struktur untuk menyampaikan informasi (Haig et al., 2006). Terbentuknya shared mental model juga merupakan mekanisme yang efektif untuk mengatasi hierarki tradisional yang umum berlaku di antara dokter dan 
tenaga kesehatan lainnya seperti subordinal untuk menyampaikan perawat (Leonard et al., 2004). kekhawatiran atau keluhan mereka Perbedaan tingkat kewenangan (power mengenai kondisi klinis pasien. Dengan distance) umumnya membuat pihak demikian, SBAR mampu mengurangi subordinat enggan menyampaikan kesalahpahaman dalam komunikasi keluhan (Leonard et al., 2004; yang sering terjadi akibat asumsi, Manojlovich, 2010). Dengan informasi yang implisit, ketidakjelasan menciptakan kerangka berpikir yang dan ketakutan untuk bertanya lebih sama, SBAR menciptakan lingkungan jauh akibat perbedaan tingkat otoritas. yang 'aman' bagi pihak dengan posisi

Tabel 1. Struktur Komunikasi dengan SBAR

\begin{tabular}{ll}
\hline \multicolumn{1}{c}{ Komponen SBAR } & \multicolumn{1}{c}{ Hal yang disampaikan } \\
\hline S (Situation) & $\begin{array}{l}\text { Jelaskan situasi yang dilaporkan: nama pelapor, } \\
\text { unit asal, nama pasien yang dilaporkan dan } \\
\text { lokasinya, alasan pelaporan / masalah yang } \\
\text { dilaporkan (apa, kapan dan seberapa parah) }\end{array}$ \\
\hline & $\begin{array}{l}\text { Jelaskan alasan pasien dirawat saat ini: diagnosis } \\
\text { dan tanggal masuk }\end{array}$ \\
& $\begin{array}{l}\text { Jelaskan riwayat medis yang penting seperti: } \\
\text { B (Background) }\end{array}$ \\
& $\begin{array}{l}\text { laboratorium, dan informasi klinis lainnya } \\
\text { Berikan penilaian pelapor terhadap keadaan } \\
\text { pasien saat ini didukung dengan hasil } \\
\text { pemeriksaan yang relevan. } \\
\text { A (Assessment) }\end{array}$ \\
& $\begin{array}{l}\text { Jikasalah secara jelas, dapat menyampaikan hal } \\
\text { yang menjadi kekuatiran }\end{array}$ \\
\hline R (Recommendation) & $\begin{array}{l}\text { Jelaskan apa yang diperlukan pelapor saat ini. } \\
\text { Berikan saran dan perjelas harapan }\end{array}$ \\
\hline
\end{tabular}

Evaluasi terhadap SBAR telah dan komunikasi antara perawat dan dilakukan di berbagai negara seperti dokter serta penurunan angka Amerika Serikat, Kanada, Australia, kematian yang tidak diharapkan Inggris, Belgia dan Belanda (Randmaa setelah SBAR diimplementasikan di et al.,2014). Hasil penelitian De sebuat RS di Belanda. Penelitian lain Meester et al., (2013) menunjukkan juga menunjukkan SBAR meningkatkan bahwa adanya peningkatan kerja sama komunikasi antara anggota tim serta 
meningkatkan budaya safety yang ditunjukkan oleh penilaian staf rehabilitasi (Velji et al., 2008). Hasil penelitian Marshall et al. (2009) terhadap simulasi rujukan melalui telepon yang dilakukan oleh mahasiswa kedokteran dan dokter muda menunjukkan adanya perbaikan dalam hal komunikasi

Teknik SBAR belum pernah digunakan dalam komunikasi antar tenaga kesehatan yang terkait dengan perawatan pasien di RS Universitas Mataram. Komunikasi efektif menjadi sangat penting dengan semakin meningkatnya tuntutan terhadap malpraktek di Indonesia beberapa waktu belakangan ini. Dengan banyaknya tenaga kesehatan yang bertugas, maka pihak-pihak yang terlibat dalam perawatan pasien menjadi semakin banyak. Diperlukan suatu pendekatan khusus agar informasi yang disampaikan utuh dan mudah dipahami sehingga keselamatan pasien tidak dipertaruhkan. Mempertimbangkan manfaat yang bisa didapat dengan meningkatnya efektivitas komunikasi antar anggota tim perawatan, maka teknik SBAR dipandang perlu untuk diperkenalkan kepada tenaga kesehatan di RS Universitas Mataram. Kegiatan pengabdian kepada masyarakat ini bertujuan untuk meningkatkan pengetahuan, keterampilan dan kepercayaan diri tenaga kesehatan dalam melakukan komunikasi lisan dalam proses handoff pasien.

\section{METODE KEGIATAN}

Luaran dari kegiatan pengabdian kepada masyarakat ini adalah agar para peserta memiliki kemampuan untuk menjelaskan handoff dan mengenali situasi yang membutuhkan handoff, memahami pentingnya struktur komunikasi dalam handoff pasien, mampu menjelaskan informasi yang perlu disampaikan pada setiap elemen SBAR serta mampu mengaplikasikan SBAR dalam proses handoff pasien. Materi disampaikan melalui ceramah interaktif dan kegiatan menonton video contoh aplikasi SBAR sebagai pemicu diskusi. Sesi ini berlangsung selama 45 menit. Selanjutnya, peserta dibagi menjadi tiga kelompok berdasarkan profesi (dokter, perawat, bidan dan profesi lainnya) untuk berlatih mengaplikasikan SBAR melalui roleplay sesuai dengan kasus yang diberikan. Role-play berlangsung selama 75 menit. Masing-masing kelompok di dampingi oleh seorang anggota tim PPM sebagai fasilitator (DPS, YPS dan TPK) dan seorang dokter spesialis yang berperan sebagai pihak yang dikonsultasikan. Enam kasus disiapkan untuk kegiatan role-play, dua kasus untuk setiap kelompok. Dalam kegiatan role-play, peserta diminta untuk melakukan persiapan sebelum mengkonsultasikan pasien dan 
menggunakan struktur SBAR untuk menyampaikan kasus pasien kepada dokter spesialis. Berikut ini adalah salah satu contoh kasus yang digunakan dalam role-play:

Anda sebagai perawat jaga di
bangsal kelas III RS UNRAM
merawat pasien dengan deskripsi
sebagai berikut:
Seorang pasien anak perempuan
menjalani tranfusi PRC sebanyak 1
kolf ( 200 cc) golongan darah A
rhesus positif dengan nomer
kantong 98657 sejak pukul 13.00.
Kondisi anak baik sebelum tranfusi
dengan kesadaran compos mentis,
HR 98 kali permenit, RR 28 kali
permenit, TD $100 / 70$ mmHg, suhu
$36,8^{\circ}$ Celcius. Pada 1 jam setelah
tranfusi diberikan yaitu ketika darah
PRC sudah masuk sekitar 100 cc,
muncul gatal dan kemerahan mulai
dari lengan dan tungkai yang
menyebar dengan cepat ke seluruh
tubuh. Dalam waktu lima menit
setelahnya, anak demam tinggi
menggigil disertai napas cepat,
keringat dingin, ujung kaki dan
tangan dingin. Anak gelisah dan
sulit ditenangkan.

\section{Sebagai perawat jaga di bangsal} tersebut, lakukan pengumpulan informasi yang dibutuhkan untuk melapor pada DPJP melalui telepon!
Sesudah melakukan role-play, peserta mengisi lembar evaluasi diri (tabel 2) dan mendiskusikan pengalamannya serta mendapatkan umpan balik dari peserta lain dan fasilitator. Peserta kembali berkumpul di kelas setelah role-play untuk diskusi (wrap up) sebelum pelatihan ditutup.

Role-play merupakan salah satu metode simulasi yang umum digunakan pada berbagai bidang ilmu untuk meningkatkan pengetahuan, sikap, ataupun keterampilan, terutama keterampilan berkomunikasi. Sebagai suatu metode simulasi, role-play fokus pada interaksi antara individu dengan individu lain. Dalam role-play peserta diminta untuk membayangkan dirinya atau orang lain berada dalam suatu situasi tertentu dan berperilaku seperti apa yang mereka pikir akan dilakukan oleh orang tersebut. Beberapa teori / prinsip pembelajaran yang menjadi landasan metode ini antara lain adalah experiential learning oleh Kolb dan reflective practice oleh Schon (Nestel \& Tierney, 2007). Metode role-play menggunakan skenario kasus telah digunakan dalam pelatihan-pelatihan SBAR di tempat lain dan menunjukkan hasil yang lebih baik dibandingkan dengan metode konvensional seperti ceramah (Wang et al., 2015; Yu \& Kang, 2017). 
Tabel 2. Lembar evaluasi diri partisipan

\begin{tabular}{|c|c|c|c|c|c|c|}
\hline No & Pernyataan & $\begin{array}{l}\text { Sangat } \\
\text { tidak } \\
\text { setuju }\end{array}$ & & & & $\begin{array}{l}\text { Sangat } \\
\text { setuju }\end{array}$ \\
\hline & & 1 & 2 & 3 & 4 & 5 \\
\hline 1 & $\begin{array}{l}\text { Saya berkomunikasi secara efektif } \\
\text { dalam proses handover ini }\end{array}$ & & & & & \\
\hline 2 & $\begin{array}{l}\text { Saya memikirkan apa yang perlu } \\
\text { saya sampaikan sebelum berbicara }\end{array}$ & & & & & \\
\hline 3 & $\begin{array}{l}\text { Saya berhasil melakukan handover } \\
\text { pasien ini }\end{array}$ & & & & & \\
\hline 4 & $\begin{array}{l}\text { Saya merasa percaya diri dalam } \\
\text { menyampaikan informasi secara } \\
\text { verbal }\end{array}$ & & & & & \\
\hline 5 & $\begin{array}{l}\text { Saya mengalami kesulitan } \\
\text { menyampaikan maksud saya }\end{array}$ & & & & & \\
\hline 6 & $\begin{array}{l}\text { Saya berhasil dalam } \\
\text { menyampaikan maksud saya }\end{array}$ & & & & & \\
\hline 7 & $\begin{array}{l}\text { Saya khawatir selama melakukan } \\
\text { panggilan telepon }\end{array}$ & & & & & \\
\hline 8 & $\begin{array}{l}\text { Saya benar-benar puas dengan } \\
\text { luaran dari panggilan telepon ini }\end{array}$ & & & & & \\
\hline
\end{tabular}

Untuk menilai perubahan elemen SBAR, evaluasi kelengkapan tingkat pengetahuan dan kepercayaan informasi dalam proses handoff diri dalam melakukan handoff menggunakan SBAR serta persiapan menggunakan SBAR, peserta diminta melakukan SBAR. Partisipan juga mengerjakan pretes dan postes diminta mengisi lembar umpan balik sebelum dan sesudah mengikuti terhadap pelaksanaan pelatihan di pelatihan serta mengisi lembar akhir sesi pelatihan. Hasil pre dan evaluasi diri. Soal pretes dan postes postes serta evaluasi diri sebelum dan terdiri dari 10 butir pertanyaan pilihan sesudah mengikuti pelatihan dianalisis ganda dengan empat pilihan jawaban. secara statistik untuk menilai Pertanyaan pretes dan postes perubahan tingkat pengetahuan dan mencakup definisi handoff, situasi keberhasilan pelatihan. yang membutuhkan handoff, informasi yang harus disampaikan dalam setiap 


\section{HASIL DAN PEMBAHASAN}

Kegiatan pengabidan kepada masyarakat berupa pelatihan SBAR bagi dokter dan tenaga kesehatan di RS Universitas Mataram ini terlaksana pada hari Selasa, 23 April 2019 di Aula RS mulai pukul 08.30 sampai dengan 12.00 WITA. Acara ini dihadiri oleh 46 peserta yang sebagian besar adalah perawat. Rincian jumlah peserta pelatihan dapat dilihat pada Tabel 3 berikut.
Tabel 3. Profesi dan jumlah peserta pelatihan

\begin{tabular}{lc}
\hline Profesi Peserta Pelatihan & Jumlah \\
\hline Dokter & 1 \\
Dokter spesialis & 5 \\
Dokter gigi & 2 \\
Perawat & 24 \\
Bidan & 3 \\
Farmasi & 3 \\
Radiologis & 2 \\
Yanmed & 1 \\
Total peserta & 46 \\
\hline \multicolumn{2}{c}{ Berdasarkan hasil pre dan } \\
postes peserta, didapatkan \\
peningkatan pengetahuan yang \\
signifikan secara statistik setelah \\
mengikuti pelatihan (tabel 4).
\end{tabular}

Tabel 4. Pengetahuan partisipan sebelum dan sesudah pelatihan

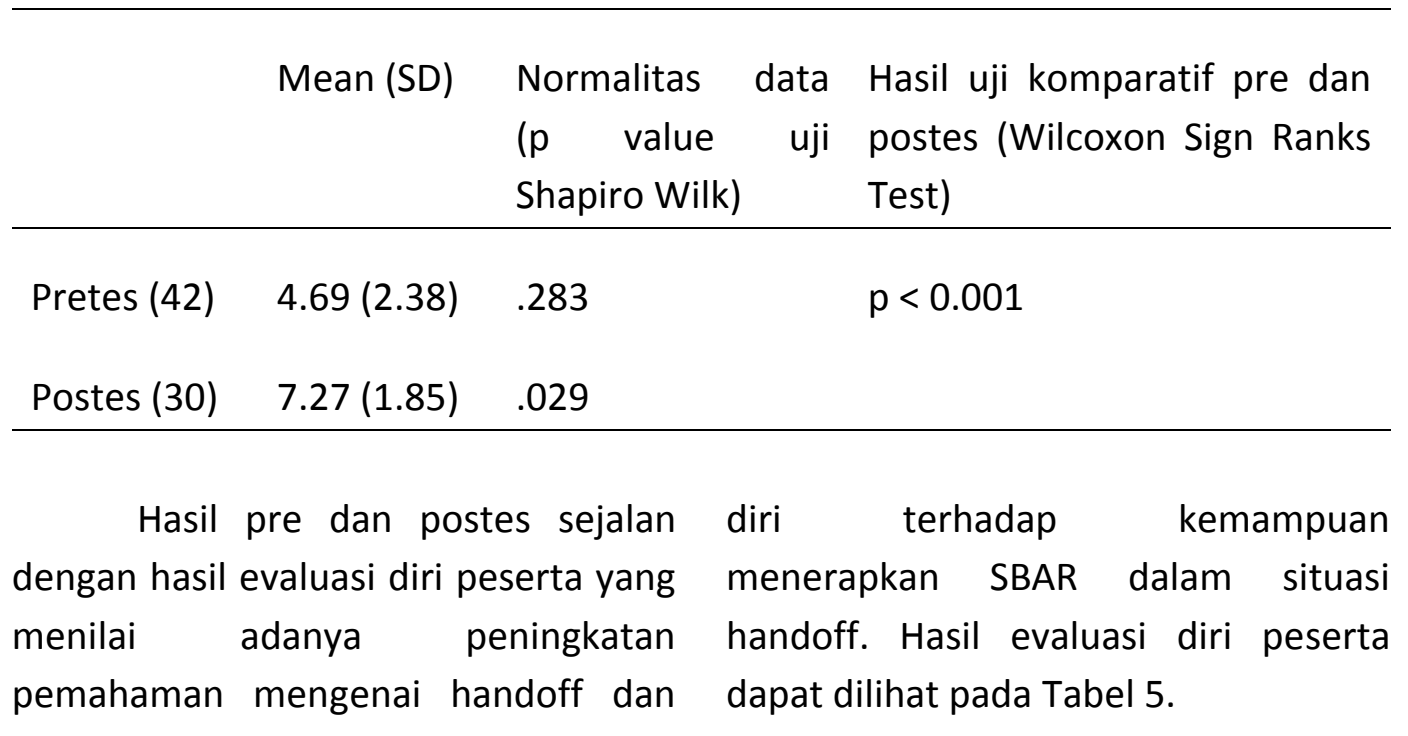

SBAR serta peningkatan kepercayaan 
Tabel 5. Evaluasi Diri Partisipan Sebelum dan Sesudah Pelatihan

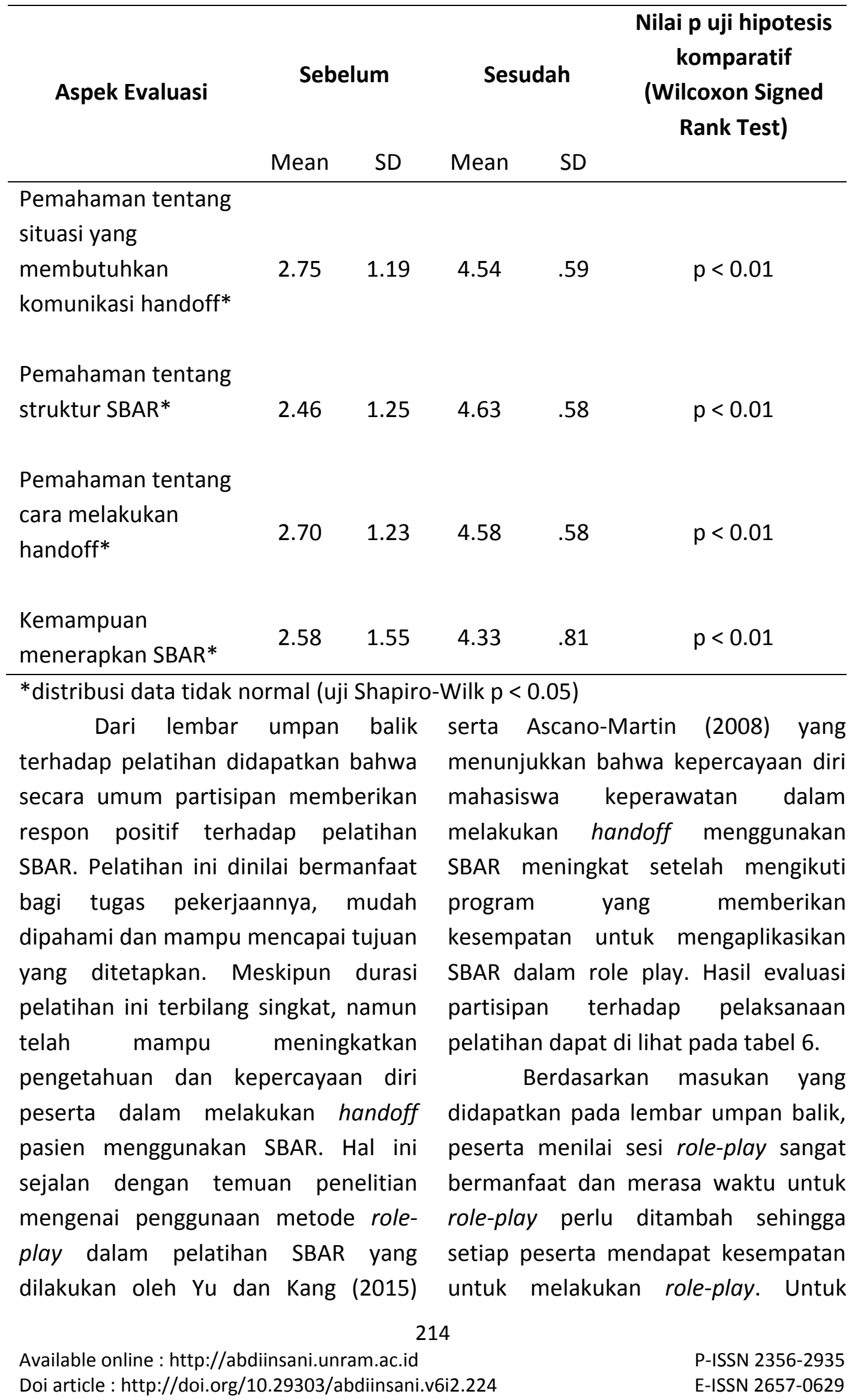


peningkatan kualitas pelatihan, terlibat dalam simulasi. Masukan peserta menyarankan perlunya lainnya adalah agar dapat diberikan menambah jenis kasus yang disiapkan contoh-contoh yang relevan untuk agar bisa profesi kesehatan lain selain profesi lain selain ketiga profesi dokter, perawat dan bidan dapat lebih tersebut.

Tabel 6. Evaluasi Pelaksanaan Pelatihan

\begin{tabular}{|c|c|c|}
\hline Komponen evaluasi & Mean & $\begin{array}{l}\text { Standar } \\
\text { Deviasi }\end{array}$ \\
\hline \multicolumn{3}{|l|}{ Materi } \\
\hline Relevan ( $\mathrm{N}=26)$ & 4.50 & .58 \\
\hline Komprehensif ( $\mathrm{N}=26)$ & 4.38 & .75 \\
\hline Mudah dipahami $(\mathrm{N}=30)$ & 4.70 & .65 \\
\hline \multicolumn{3}{|l|}{ Handout (modul/buku panduan) } \\
\hline Mendukung materi presentasi $(\mathrm{N}=26)$ & 4.54 & .58 \\
\hline Memberikan informasi tambahan yang berguna $(\mathrm{N}=28)$ & 4.57 & .69 \\
\hline Jelas dan terorganisir $(\mathrm{N}=28)$ & 4.61 & .69 \\
\hline \multicolumn{3}{|l|}{ Jalannya workshop } \\
\hline Well paced $(\mathrm{N}=27)$ & 4.44 & .80 \\
\hline Waktu istirahat cukup ( $N=27$ ) & 4.04 & .89 \\
\hline Sesi ceramah dan aktivitas seimbang ( $N=29$ ) & 4.55 & .57 \\
\hline $\begin{array}{l}\text { Kegiatan pembelajaran dalam workshop bermanfaat } \\
(\mathrm{N}=29)\end{array}$ & 4.76 & .51 \\
\hline \multicolumn{3}{|l|}{ Penyampai materi } \\
\hline Menyampaikan materi dengan jelas ( $N=27)$ & 4.67 & .55 \\
\hline Mempersiapkan sesi dengan baik (N=27) & 4.52 & .75 \\
\hline Responsif terhadap pertanyaan partisipan ( $N=29)$ & 4.66 & .55 \\
\hline $\begin{array}{l}\text { Workshop berhasil mencapai tujuan yang ditetapkan } \\
(n=30)\end{array}$ & 4.27 & .64 \\
\hline \multicolumn{3}{|l|}{ Informasi yang didapatkan dari workshop } \\
\hline Sesuai harapan ( $N=27$ ) & 4.59 & .57 \\
\hline Berguna untuk diaplikasikan dalam tugas $(\mathrm{N}=29)$ & 4.76 & .51 \\
\hline
\end{tabular}


Keterangan: Peserta memberikan penilaian menggunakan skala Likert 1 - 5 (1=sangat tidak setuju, $5=$ sangat setuju)

\section{Evaluasi \\ pelatihan}

menunjukkan hasil yang baik pada dua level pertama dari empat level evaluasi Kirkpatrick, yaitu level 1 - reaksi (kepuasan terhadap pelatihan) dan level 2 - pembelajaran (adanya peningkatan pengetahuan). Sejauh mana pelatihan ini mampu mempengaruhi perilaku peserta dalam menjalankan tugas pekerjaannya (level 3 - Perilaku) serta luaran atau manfaat pelatihan ini bagi kualitas pelayanan dan keselamatan pasien (level 4 - outcome) belum dapat dievaluasi segera setelah pelatihan. Namun demikian, pelatihan ini merupakan awal yang baik untuk memperkenalkan SBAR di RS Pendidikan UNRAM. Untuk memastikan SBAR dipraktikkan dalam pekerjaan sehari-hari, diperlukan kebijakan dari manajemen RS untuk memasukkannya ke dalam prosedur operasional baku komunikasi dalam proses handoff dan implementasinya perlu di evaluasi.

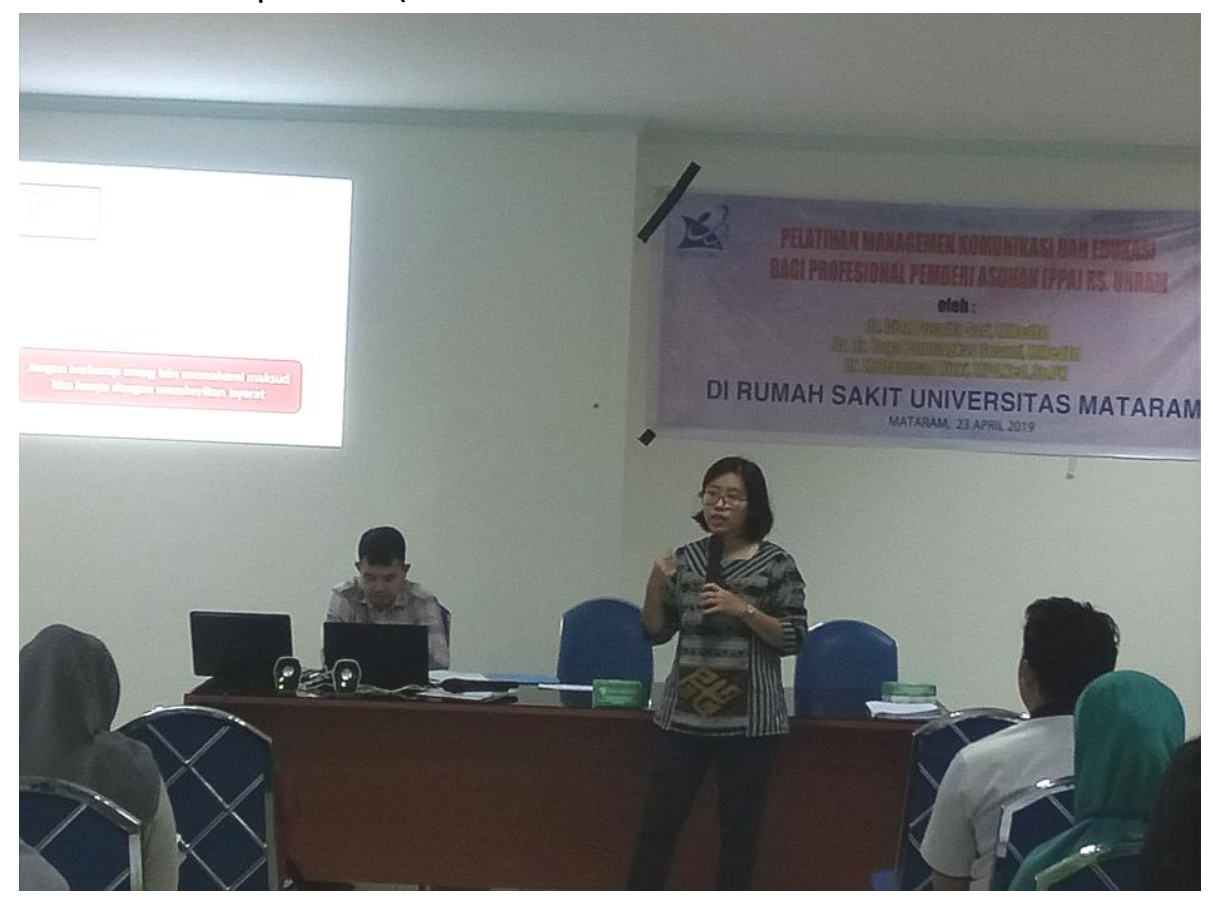

Gambar 1. Sesi ceramah interaktif 


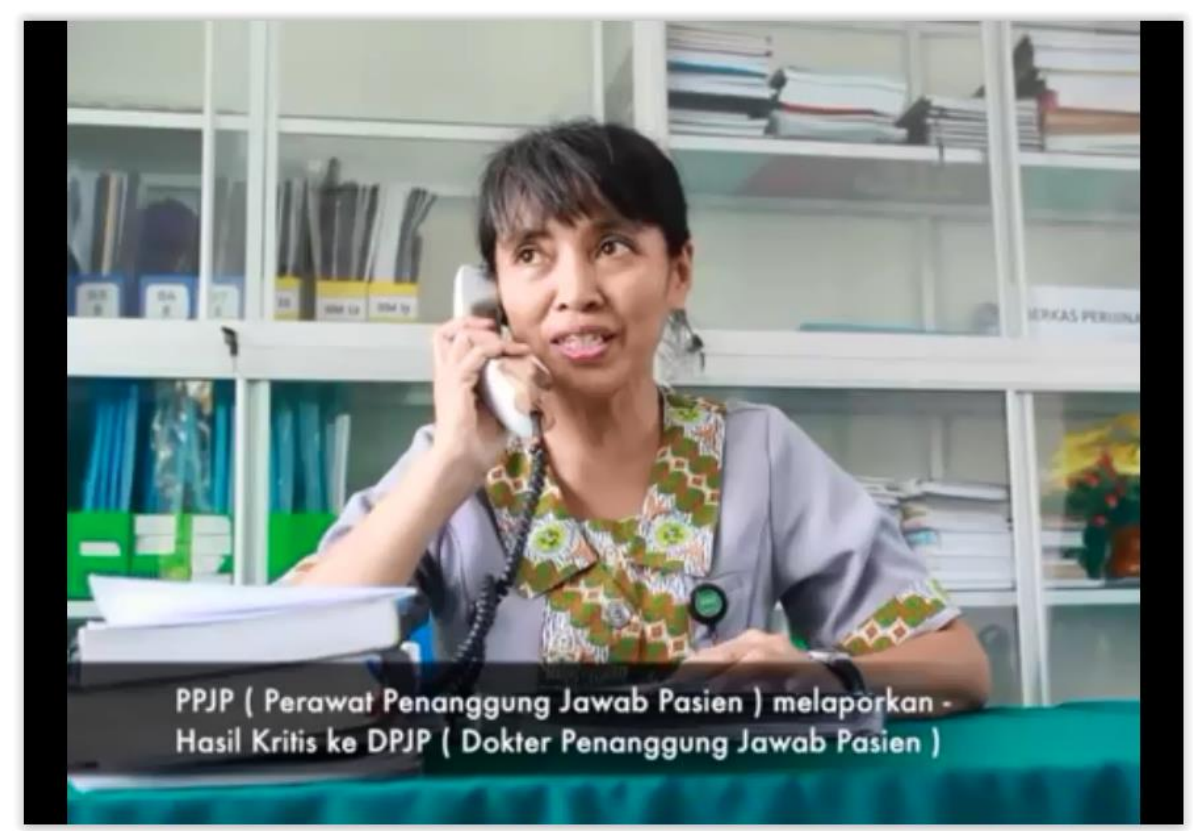

Gambar 2. Video yang diputar pada sesi menonton video

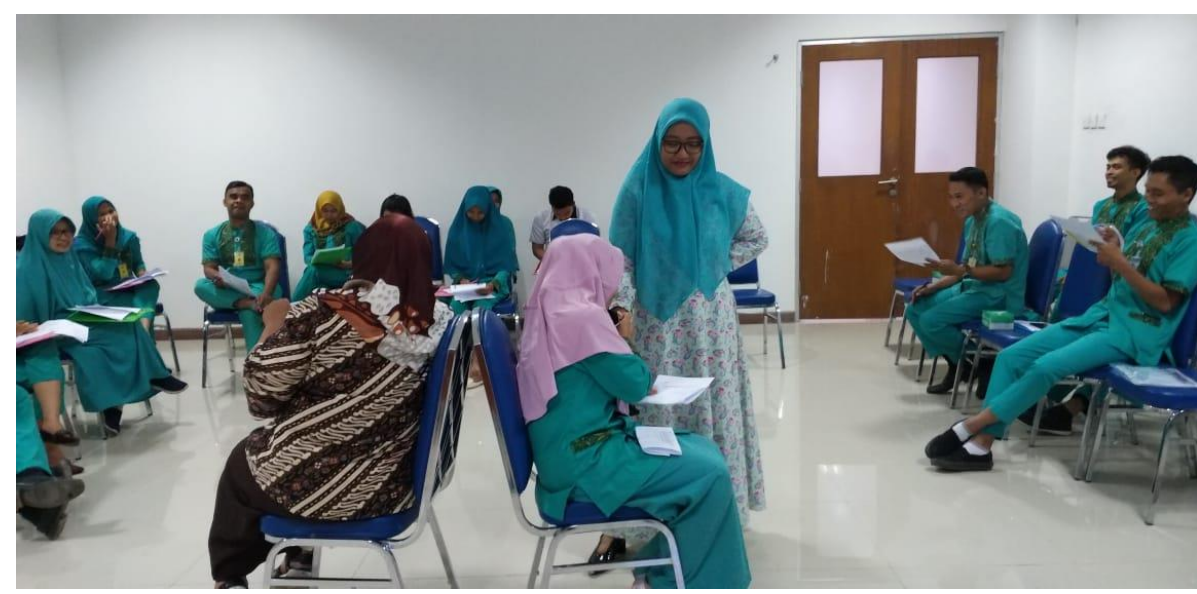

Gambar 3. Role-play: perawat berkonsultasi dengan Dokter Penanggung Jawab Pasien (DPJP) melalui telepon. Dokter dan perawat duduk saling membelakangi agar dapat menghayati situasi komunikasi melalui sambungan telepon

\section{KESIMPULAN DAN SARAN}

Pelatihan SBAR yang dilaksanakan di

RS Universitas Mataram telah mampu meningkatkan pengetahuan, keterampilan dan kepercayaan diri ndoff pasien yang ditunjukkan oleh peningkatan nilai postes dibandingkan pretes, hasil evaluasi diri peserta tenaga kesehatan di RS untuk menggunakan struktur komunikasi SBAR dalam proses ha mengenai kemampuannya menggunakan SBAR dan hasil evaluasi terhadap pelatihan. Namun demikian, 
agar SBAR diterapkan dalam tugas pelayanan pasien, pelatihan ini perlu ditindak lanjuti oleh pihak RS dengan menetapkan kebijakan yang mendukung penerapan SBAR oleh dokter dan tenaga kesehatan.

\section{UCAPAN TERIMA KASIH}

Tim pelaksana kegiatan pengabdian kepada masyarakat ini mengucapkan terima kasih kepada: Fakultas Kedokteran Universitas Mataram dan Lembaga Penelitian dan Pengabdian Kepada Masyarakat yang telah mendanai kegiatan ini melalui sumber dana DIPA BLU (PNBP) tahun 2019; Rumah Sakit Pendidikan Universitas Mataram yang telah membantu terselenggaranya pelatihan ini; dr. Rizkinov Jumsa, Sp.OG dan dr. Basuki Rahmat, Sp.JP (K) yang telah berkenan menyiapkan kasus untuk sesi simulasi dalam pelatihan ini.

\section{DAFTAR PUSTAKA}

Agency for Healthcare Research and Quality (2012) Situation monitoring: classroom slides: TeamSTEPPS Long-Term Care Version: Module 4.Available from

http://www.ahrq.gov/professio nals/education/curriculumtools/teamstepps/longtermcar e/module4/slltcsitmonitor.html Accessed on March $17^{\text {th }} 2014$.
Ascano-Martin, F., (2008) Shift report and SBAR. Strategies for clinical post conference. Nurse Education, 33, pp. 190-191. http://dx.doi.org/10.1097/01.N NE.0000334779.90395.67.

Cohen, M.D. \& Hilligoss, P.B. (2010) The published literature on handoff $s$ in hospitals: deficiencies identified in an extensive review. Qual Saf Health Care 19, p. 493-497.

Cohen, M.D., Hilligos, B. \& KajdacsyBalla Amaral, A.C. (2012) A handoff is not a telegram: an understanding of the patient is co-constructed. Critical Care 16 (303) p. 1 - 6

De Meester, K., Verspuy, M., Monsieurs, K.G., et al. (2013) SBAR improvesnurse-physician communication and reduces unexpected death: apre and post intervention study. Resuscitation 84, p. 1192-1196. Haig, K.M., Sutton, S. \& Whittington, J. (2006) SBAR: A shared mental model for improving communication between clinicians. Journal on Quality and Patient Safety 32 (3), p.167 $-175$

Manojlovich, M. (2010) Nurse/physician communication through a sensemaking lens. Med Care 48(11), p. 941-946. 
Marshall S, Harrison J, Flanagan B.(2009) The teaching of a structuredtool improves the clarity and content of interprofessional

clinicalcommunication. Qual Saf Health Care18, p. 137-140.

Nestel, D. \& Tierney, T. 2007. Role-play for medical students learning about communication: guidelines for maximizing the results. BMC Medical Education, 7 (3), doi:10.1186/1472-6920-7-3

Randmaa, M., Martensson, G. Swenne, C.L. \& Engstrom, M. (2014) SBAR improves communication and safety climate and decreases incident reports due to communication errors in an anaesthetic clinic: a prospective intervention study. BMJ Open 4 (e004268), p. 1 - 8 Velji, K., Baker, G.R., Fancott C, et al. (2008) Effectiveness of an
adaptedSBAR communication tool for a rehabilitation setting. Healthcare Quarterly11, p. 7279.

WHO Collaborating Centre for Patient Safety Solutions (2007) Communication during patient hand-overs. Patient Safety Solution 1(3), p.1-4

Yu, M. \& Kang, K.J., (2017) Effectiveness of a role-play simulation program involving the SBAR technique: a quasi experimental study. Nurse Education Today, 53, pp. 41-47 doi:10.1186/1472-6920-7-3

Yu, M., Kang, K.J., (2015) SBAR report competency and communication clarity of handover in Korean nursing students. International Journal of Bio-Science and BioTechnology, 7, pp. 189-200. http://dx.doi.org/10.14257/ijbs bt.2015.7.6.19. 